\title{
Whose ethics and for whom? Dealing with ethical disputes in agri-food governance
}

\author{
Talis Tisenkopfs $^{1}{ }^{1}$ · Emils Kilis ${ }^{1} \cdot$ Mikelis Grivins ${ }^{1} \cdot$ Anda Adamsone-Fiskovica $^{1}$
}

Accepted: 28 January 2019 / Published online: 7 February 2019

(c) The Author(s) 2019

\begin{abstract}
In contemporary societies there is a continuous process of creation and destruction of ethics. Shared norms are fuzzy, as actors tend to share core principles but interpret them differently. In this paper we analyse three cases of ethical dispute in the agri-food sector by employing the distinction between matters of fact and matters of concern proposed by Bruno Latour. We further suggest that ethics in the agri-food industry should be considered in relation to collective goals such as sustainability and social justice. To expand the role of ethics it is necessary to broaden the view on who is responsible and how for the manifold challenges faced in food production, distribution and consumption. We contend that reflections on the relationship between ethics and sustainability must go beyond an anthropocentric approach and also consider the welfare of non-human nature (e.g. land, animals). Our study suggests that the boundary between politics and ethics is fluid and governing institutions have a role to play in ethicisation of food systems along with industry and civil society. Any resolution of matters of concern is neither innocent, nor impartial. Ethical responses to food system challenges are rather to be established through dialogue and alignment of ethical practices.
\end{abstract}

Keywords Agri-food system · Ethics · Disputes · Sustainability · Matters of fact · Matters of concern · Responsibility · Governance

$\begin{array}{ll}\text { Abbreviations } \\ \text { ANT } & \text { Actor-Network Theory } \\ \text { FVS } & \text { Food and Veterinary Service } \\ \text { MA } & \text { Ministry of Agriculture } \\ \text { LAOCC } & \text { Latvian Agricultural Organization Cooperation } \\ & \text { Council } \\ \text { TS } & \text { Tukuma Straume }\end{array}$

Talis Tisenkopfs

talis.tisenkopfs@1u.lv

Emils Kilis

emils.kilis@gmail.com

Mikelis Grivins

mikelis.grivins@gmail.com

Anda Adamsone-Fiskovica

anda@1za.lv

1 Baltic Studies Centre, Kokneses prospekts 26-2,

Riga LV1014, Latvia

\section{Introduction}

In ethics, the promise of closure, or at least temporary consensus, through reasoning is widely shared. In an attempt to disrupt these promises, it may help to call "what to do?" a political question. The term politics resonates openness, indeterminacy. It helps to underline that the question "what to do" can be closed neither by facts nor arguments. That it will forever come with tensions - or doubt. In a political cosmology "what to do" is not given in the order of things, but needs to be established (Mol 2002, p. 177).

It is seldom questioned that our agri-food systems should strive to be more sustainable. However, the thematically inclusive and broad nature of the term sustainability, and the multitude of actors whose interests and needs have to be taken into account often lead to divergent interpretations as to the best way to proceed. As Ben Mepham has suggested, "[e]thical dilemmas arise when there appear to be good reasons for performing opposing actions" (Mepham 1996, p. 102). Such dilemmas and the discussions they have 
given rise to have become increasingly prominent in relation to food and agriculture.

There is an increasing recognition that the future of agrifood systems and their contribution to sustainable development goals will depend not only on technological fixes but also on their capacity to embrace a wide spectrum of social and cultural values, including ethical considerations (Food 2030). This is particularly true with regard to food system governance.

In this article we explore how ethics shapes relationships between actors in agri-food systems, what contestations and dilemmas emerge in this process and how ethically-driven food system transformations could be facilitated by appropriate governance arrangements.

We define ethics as the praxis of value deliberation and enforcement in mutual norms of moral conduct. We look at various moral concerns in food systems (including the widening sphere of moral subjects and objects), deliberation of ethical concerns and distribution of responsibility among various types of actors. We also examine the mechanisms by which ethical considerations are raised and introduced in agri-food systems governance, and whether they actually succeed to achieve changes. If we are to transform the current agri-food chains into transparent and democratic networks, this cannot be achieved only by regulation. There is a need for much stronger inclusion of values in food governance, first of all-recognition of ethics as a transversal dimension of sustainability (Brunori et al. 2016; Kirwan et al. 2017). It is equally important to establish a connection between ethics and democratic governance procedures.

In this article we have chosen to focus on three distinct cases of ethical dispute which have brought ethical considerations to bear on questions such as animal welfare in the agri-food industry, sustainable diets, and green energy production in agriculture. The three cases attempt to represent micro, meso and macro levels at which ethical considerations interfere with other relevant sustainability dimensions, such as economic, environmental and social sustainability. The first case revolves around the public dispute over the outbreak of a serious (and often fatal) dog disease and its connection to a local brand of pet food. The case epitomises the links between ethics and economic and social sustainability at the regional level. The second case focuses on the decision by a private school to provide only vegetarian meals to children, and the resulting response from the state. The case represents a relationship between ethics and ecological and social sustainability at the micro community level. The third case explores a macro level promotion of biogas production as a source of green energy where economic and environmental sustainability interests clash and ethics becomes a major challenger of the development path.

While not all of these cases have been explicitly framed in ethical terms, they all represent situations that bear upon the role of ethical considerations in the context of agri-food governance and the responsibilities of various actors involvedespecially the state, industry and civil society. In analysing these cases, we employ the distinction between matters of fact and matters of concern introduced and elaborated by Bruno Latour (2004a, b, 2005, 2008) and suggest that it is a useful lens through which to analyse cases of ethical dispute. The three cases are representative of different uncertain and contested matters of concern that illustrate clashes and frictions between uncertainty, established ways of doing things, and economic interests.

By looking at these cases we seek to make a contribution to discussions of the role of ethics in agri-food governance. By focusing on situations of ethical uncertainty we draw attention to (i) the frictions attendant to negotiating conceptions of ethical conduct, and (ii) the highly situational and precarious nature of ethics in the agri-food system. We, therefore, focus on the complexities attendant to ethical disputes and reflect upon the resulting implications for an ethics of agri-food governance that seeks to ensure sustainable (understood broadly) futures.

The article is divided into four sections. The first section outlines the theoretical framework, which synthesises insights from different fields, including ethics, sustainability research, and science studies. The second section is devoted to descriptions of the three case studies. The third section brings together the manifold dimensions of ethical disputes identified in the cases, and analyses them with the theoretical tools outlined in the first section. The fourth section advances the discussion about the ethicisation of agri-food governance and distribution of responsibility.

Overall, this article demonstrates that open ethical disputes in agri-food systems represent a rich source of insights into the divergent values and interests at stake, and the governance arrangements used in regulating, but not necessarily efficiently settling, the varied clashes with regard to sustainable practices. To ensure the position of ethics as one of the cornerstones of sustainability of agri-food systems it is necessary to broaden the view on who is responsible, and how, for the manifold challenges faced in food production, distribution and consumption.

\section{Analytical framework}

\section{Linking ethics and sustainability}

Food ethics is an interdisciplinary field that considers issues such as consumer choices, the environmental and health consequences of consumption and production holistically and "seeks to connect the various choices all along the complex value chain" (Kaiser and Algers 2016, p. 3). While we commend the holistic conception of food ethics, there are 
currently different academically respected ways of approaching ethics and morally appropriate conduct that reflect differences in background assumptions (Jennings 2010; Kibert et al. 2011). However, if we move away from the level of individual choices (as consumers) to decisions that bear upon collective well-being (as citizens), there are areas of overlapping concern that provide a foundation of sorts for formulating a more concrete framework for discussion. Specifically, we suggest that ethics in the agri-food sector should be considered in relation to collective goals such as sustainability and social justice (MacMillan and Dowler 2012). In approaching agri-food from the perspective of ethics it is necessary to broaden the object and subject field of ethical interaction. Agri-food ethics calls for a wider definition of ethical alliances, shared responsibility, and fuzzy non-human imperative targets if to compare with ethics in relationship between two individuals.

For non-philosophers, food ethics evokes objectives relating to social justice and sustainability and enjoins citizens to achieve these objectives by making ... choices that have desirable consequences (Thompson 2016, p. 61).

For the purposes of this article we approach ethics in the agri-food sector as a field of social, economic, political and legal struggles that bear upon collective goals and the methods most appropriate to achieving them. We look at the ethics of collective (rather than individual) decisions and actions that bear upon goods that are collectively articulated and achieved (see Kibert et al. 2011). While this means that the boundary between politics and ethics becomes fluid (Vlaholias-West et al. 2018), we contend that such an approach is most appropriate for looking at the role of ethics in ensuring the sustainability of the agri-food sector, and reflecting upon the impact it has on different groups, local communities and entire societies.

Ethics in the agri-food has been previously articulated by Mepham (1996), Thompson (2007b, 2016) and Kibert et al. (2011) as collective arrangements and policy decisions that meet the goals of a society and the needs and interests of the various disparate groups within society (UK Health Forum 2018). We approach ethics as a discussion regarding morally acceptable and socially just and responsible conduct that creates change in food systems and makes a positive contribution to sustainability.

In recent scientific debate, the concept of sustainability has transformed and become broader, more thematically inclusive and holistic. Whilst the economic dimension has historically been present in conceptions of sustainability (Caradonna 2014), contemporary discussions are more explicit about the interrelationship of environmental, economic and social sustainability (Kibert et al. 2011). Health, ethics and governance have been suggested as indispensable dimensions of sustainability (Morgan 2010; Galli et al. 2016). We suggest that, when thinking about ethics in the context of agri-food governance, it is important to consider these different dimensions of sustainability and the ethical issues that arise in situations where more than one dimension of sustainability is at play. In addition, we contend that reflections on the relationship between ethics and sustainability must go beyond an anthropocentric approach and also consider the welfare of non-human nature (e.g. land, animals).

\section{From certainty to dispute: matters of fact and matters of concern}

In order to tackle issues related to the role of ethics in agri-food governance, this paper employs analytical tools drawn from actor-network theory. ANT is an approach that emerged within science studies and can be used to analyse the formation of durable socio-material networks and associations involving heterogeneous agents. We contend that the emphasis on process makes ANT well-suited for an analysis of open-ended disputes, and the insistence on the agency of non-humans broadens the range of entities whose needs have to be taken into account when acting ethically. Furthermore, by focusing on contested issues and "feeding off uncertainties" (Latour 2005, p. 115) researchers can learn new lessons about processes that complicate agri-food governance, particularly if we approach ethical disputes as instances of matters of concern.

The distinction between matters of fact and matters of concern features prominently in publications by Bruno Latour. While a clear description of these categories is elusive, we suggest that Latour employs this distinction to juxtapose ways of framing processes that involve both technical (e.g. scientific/technological) and normative (e.g. ethical/political/legal) elements, and complicate the fact/value distinction.

According to Latour, discussions proceeding on the basis of matters of fact treat states of affairs as settled and emphasise the seemingly indisputable elements of reality that frame and limit the way we should talk about a particular topic ("the facts"). It is a kind of discourse that focuses on ostensibly incontrovertible aspects of phenomena (be they social or natural) that exist whether you like them or not. It aims to be a neutral and accurate description of the status quo.

While the use of research and verified claims appears desirable, Latour points out a potential problem with uncritically accepting facts as innocent descriptions of a settled state of affairs. He suggests that the emphasis on facts generally ignores the network of associations necessary to construct and introduce specific claims about reality into established ways of doing and thinking about phenomena. 
What is wrong with the way the word "fact" is currently used? It obliges us, in the first place, to omit the work required in order to establish the persistent, stubborn data (Latour 2004b, p. 95).

Latour contends that matters of fact, in reality, arise from durable networks of mutually reinforcing agents (both human and non-human) that, crucially, manage to divert attention from their contingency and thus appear to validate specific claims as self-evident, indisputable features of reality, even though they are the result of human and non-human labour.

Reality is not defined by matters of fact. Matters of fact are not all that is given in experience. Matters of fact are only very partial and, I would argue, very polemical, very political renderings of matters of concern (Latour 2004a, p. 232).

Furthermore, the rhetorical and practical potency of factual claims is often deployed to foreclose political and ethical disputes. In short, matters of fact are deployed to limit the space afforded to normative and axiological reflection, thus eliminating alternative material and ethical possibilities, whilst diverting attention from the conditions that make such facts possible.

Matters of concern, on the other hand, are instances when the contingent and heterogeneous associations of agents, whose discrepant views of the situation are the cause of dispute and disagreement, are open to view and have yet to be concealed.

It is the same world, and yet, everything looks different. Matters of fact were indisputable, obstinate, simply there; matters of concern are disputable, and their obstinacy seems to be of an entirely different sort: they move, they carry you away, and, yes, they too matter (Latour 2008, p. 39).

As noted above, matters of fact aim to frame a state of affairs as fixed, stable and indisputable. Matters of concern, on the other hand, are openly contested and emerge during moments of crisis and uncertainty. In such situations the distinction between facts and values is blurry. Different associations of agents attempt to propose and stabilise their own version of reality and argue for the pertinence and stability of candidate factual claims. The desirable course of action (or the "right" thing to do) is in dispute due to conflicting renderings of the situation in question.

The key thing to take away from this is that matters of concern will not necessarily be resolved by appealing to facts since different parties see the object of dispute (and therefore the pertinence of specific factual claims) differently.

It is the thing itself that has been allowed to be deployed as multiple and thus allowed to be grasped through different viewpoints, before being possibly unified in some later stage depending on the abilities of the collective to unify them (Latour 2004b, p. 116).

By focusing on matters of concern we are in a better position to take account of the discrepant articulations of issues in which ethical questions (what is the right thing to do/ right way to proceed) are tied to specific factual renderings of the situation (various candidates for matters of fact) yet require resolution for peaceful co-existence going forward. Furthermore, it is important to bear in mind that closures of matters of concern are not innocent and impartial. The decision as regards what to do is not a matter of following existing rules, for it is these rules that a matter of concern questions. Rather, as the opening quote suggests, the solution needs to be established through practice.

\section{Case studies}

With reference to the framework outlined above we have chosen three distinct cases of ethical dispute in Latvia that can each be positioned in a different segment of the sustainability matrix where at least two sustainability aspectseconomic/environmental, environmental/social, and social/ economic - are always involved, and that affect a heterogeneous group of agents. Furthermore, the examples illustrate the tensions that permeate attempts to prioritise one form of sustainability over another. On top of it, the case selection was done to choose cases that represent ethical disputes at the micro, meso and macro levels of agri-food systems and where closure has not yet been achieved. All cases are multi-actor interfaces with the presence of the government, civil society and industry. To exemplify ethical tensions we have selected cases which have been addressed in court by employing legal procedures.

\section{Case A: deadly or not?}

In 2014, veterinarians in Latvia started noticing that an unusually high number of dogs were being diagnosed with an illness causing damage to the oesophagus (megaesophagus). Initially, it was mainly veterinary professionals and a group of dog owners who were alarmed by the sudden increase in the incidence of the disease. Even before any evidence was presented, rumours spread among dog owners that a local dog food brand Dogo produced by the company Tukuma Straume (hereafter-TS) was the cause. Dog owners raised the possibility that the brand might contain forbidden substances. Meanwhile, veterinarians were gathering information on the sick dogs to present data-based evidence on what could be causing the disease. The data revealed that $94 \%$ of 
the owners of the dogs suffering from the disease had eaten Dogo.

The conclusion attracted a great deal of controversy. First, up until then the perception was that the disease was genetically caused. Second, the study only included the identified sick dogs, and it was suggested that a high number of affected dogs had remained outside the sample. Third, TS was often referred to as a local success story-a producer that has been successfully competing with international brands. These aspects meshed together and were exacerbated by the personal guilt felt by many veterinarians, as many of them had been involved in distributing Dogo to their clients.

The study indicated a correlation between the consumption of Dogo and the disease, but did not provide an explanation as to how Dogo could have caused the disease. More research was needed to explain the connection between Dogo and the disease. The Ministry of Agriculture (hereafter-MA) responded to the claims made by veterinarians and allocated funds to study samples of Dogo. The Food and Veterinary Service (hereafter-FVS) and the Institute of Food Safety, Animal Health and Environment (hereafterBIOR) were instructed to allocate internal funds (9000 and 25,000 euros respectively), and the MA added an additional 10,700 Euros. The study initiated by the MA ended inconclusively in 2015 . To come to any conclusions the study had to be continued, and veterinarians urged the Ministry to allocate additional funds.

By then some powerful farmer organisations were publicly criticising the Ministry's decision to get involved in the scandal. In January 2016, the Latvian Agricultural Organization Cooperation Council (hereafter-LAOCC)-proclaimed that the state should protect local producers against unsubstantiated accusations. LAOCC also claimed that carrying out research on pets is an ineffective use of funds that could be allocated for research on agricultural priorities. Furthermore, the Ministry decided to cut the funding for follow-up studies.

The study eventually received support from an unexpected source. In February 2016, TS offered 32,000 euros to the veterinarians to finish the study. TS claimed that it was willing to offer the money without any strings attached, giving researchers full independence. However, the veterinarians rejected the proposal, citing the long conflict between the two sides and the loss of credibility that might come with accepting funds from a producer that is being investigated.

Meanwhile, confirmed cases of the disease continued to appear. In March 2016 alone, veterinarians registered 24 suspected cases of the disease. A year and a half after the problem has been first identified a solution had not been found. The government had withdrawn its support and actors exploring the case had met stiff opposition from farmers' organisations. However, the problem had become publicthe issue had attracted the interest of the mass media who keenly reported on the development of the case and accused the government and TS of inaction.

Meanwhile, TS was working hard to identify arguments it could use to convince the general public and dog owners that Dogo was safe. In an International Pet Industry FairPet Expo 2016 TS distributed an information pack which included a translation of a scientific article published in Poland claiming to offer an overview of scientific evidence on oesophagus dilatation and the results of the tests conducted by FVS (indicating that no violations were found in the samples). The critics, however, noted that (i) the translation of the article was intentionally misleading to present the situation in a favourable light and (ii) FVS were only testing for a fraction of the possible harmful substances.

It was clear that the opponents were not able to find common ground on how to move forward and where criticising methodological decisions and motivations of the other side. The veterinarians used public support to crowd-source the funds needed to continue the study; TS stated that it would hire international experts to conduct a quality assessment of the dog food it produces.

The public nature of the conflict lead to a situation in which an increasing number of actors publicly aligned with one of the two groups. For example, a prominent mathematician published his calculations suggesting that consumption of the particular brand of pet food increases the probability of illness 115 times (Ambainis 2016). Interestingly, this opinion provoked a response from the Ministry which published a view of another independent researcher who neglected the criticism (ZM 2016).

With the number of identified cases declining in the second half of 2016, the conflict subsided, however, the sales of Dogo dropped fivefold. In September 2016, the Latvian Veterinary Association held a seminar "Outbreak of megaesophagus/polyneuropathy in Latvian dogs: report of investigators and discussion" where the results of the study funded by crowdsourcing were presented. The event was also attended by representatives of European professional organisations. The report was inconclusive regarding what had caused the illness. Researchers indicated that lower levels of particular ferments were found in the brains of dogs that had died from the disease, which is often associated with pesticide poisoning. However, the report also concluded that the pesticides commonly associated with the loss of this particular ferment were not found in the dogs or the food they had consumed. On the whole, researchers concluded that the link between the spread of disease and the particular brand was unquestionable.

The event was overshadowed by the fact that representatives of TS were not allowed in the seminar. Furthermore, representatives of TS contended that it was unacceptable that a small group of people can attack a well-established local enterprise without having clear scientific evidence of 
the producer's wrongdoing. According to TS, the goal has always been to open the market for foreign competitors. TS claimed that it wanted to receive compensation for the losses this conflict has caused, and suggested that the responsible parties would be accountable for 458,411 euros in losses. The demands also included that some of the leading proponents of the accusations would be prohibited from working as veterinarians. Later on, representatives of TS claimed that suing the veterinarians has proved to be a successful strategy and has resulted in silencing them.

In conclusion, although it is impossible to offer a conclusive statement regarding the connection between the disease and the content of Dogo, there are a number of other problematic aspects. First, attention needs to be paid to the nature of the relationship between TS and the MA. The Ministry clearly favoured the interpretation of TS and there were political connections between the company and the Ministry as TS had made donations to the political party of the minister. Second, the research was restrained by the involved stakeholders to avoid that a more conclusive linkage between dog food and disease could be uncovered. Rather than forming a common ground to support decision making, evidence has been deployed and challenged without reaching a consensus. Finally, the case illustrates the multiplicity of the object of the dispute. For veterinarians, the battle was about saving dogs and convincing the general public that concerns over food safety also applied to non-humans. For TS, the affair was an attempt to damage their reputation. Matters of concern were not translated into mutually acceptable ethical practices.

\section{Case B: good intentions, illegal practices}

Our second case study is a private school initiative to provide organic vegetarian school meals that was challenged by the FVS. The basis for the objection was the school's failure to comply with officially mandated nutritional regulations (Grivins et al. 2018).

Ikšķile Free School was founded in a small community near Riga in 2010 with the slogan "We need to bring changes that we want to see in the world". The founders were a group of educated and well-situated parents who wanted their kids to obtain a different kind of education-more involved and responsible, less structured.

The school quickly grew in terms of functions it was working with. From the beginning it was claimed that kids should learn more from and about nature. Food was one of the educational topics. The school engaged in various local initiatives, established a garden that was maintained according to the principles of permaculture, became a local direct purchasing point, established a pop-up restaurant, created a seed bank, employed a highly qualified cook, joined the Eco-School movement, and became a pioneer of providing its pupils with vegetarian meals. Despite the complex web of activities, the school was not looking for a way to challenge the food system as a whole. The main goal was to impart a critical and responsible attitude to children education, including food education.

Most of the school's initiatives were complementary: seeds stored in the seed bank were planted in the garden and the garden provided some of the products used in the school kitchen, while other products were purchased from local farmers. Participation in the Eco-School movement motivated to monitor food waste; while the pop-up restaurant served as an opportunity for parents to gather and try the meals their kids eat on a daily basis (kids were involved in cooking and serving meals at these events).

In the first year of operation the school managed to attract EU funding to install a kitchen, however, funds were insufficient to purchase all the necessary equipment to work with meat. After consulting with parents, the school decided to offer only vegetarian meals that were morally acceptable to most parties involved. Vegetarian products were organic, locally-sourced, and the meals served were nutritious and attainable for affordable price. The school has continuously invested in kitchen equipment, certification, training of cooks, but it stayed with decision to serving only vegetarian meals.

In practice, serving vegetarian biological meals for affordable prices requires considerable labour input. Around one-third of the products used in the kitchen are grown in the school's garden that is currently undergoing a certification process to become an organic garden. The garden is maintained by parents, pupils and school staff. The school has used EU funds to buy freezers and renovate the basement to store vegetables. The school hired a nutritionist to develop vegetarian menus so that the kids would receive all the vitamins and nutrients they need. Planning and implementing an independent school meal system required commitment of the staff and voluntary work of the parents. Vegetarian meals were a manifestation of the school's environmental principles and health goals while ensuring that the meals were also economically accessible to all pupils.

This approach, however, was in conflict with the national guidelines for nutritional norms of school meals. The Cabinet regulations state that all pupils should have their weekly portion of meat (the amount of meat depends on the age of the pupil). In 2016, the FVS inspected the school and ordered it to (i) pay a 50 euro fine for failing to comply with government regulations and (ii) reintroduce meat in school diet. The FVS argued that parents' preferences cannot trump national regulations.

The school sued the FVS. The principal of the school claimed on national television that the real problem was that the school serves vegetarian meals openly. According to her, many schools do it, yet they publicly pretend that they do 
not. The school was ready to fight for change in the system. Some of the parents who were lawyers assisted with legal matters. Consequently, the school won the case against the state institution which was unprecedented. However, the decision of the Administrative District Court had the power to lift the fine, but it could not repeal regulations. Not satisfied with the results, FVS appealed the case to which the school answered that they were ready to take the case to the European Court of Human Rights.

The court invited nutritionist organisations to provide expert opinion regarding whether vegetarian meals could provide the nutrients required to ensure the health of the pupils. Independent experts expressed their support for vegetarian diets claiming that (i) the existing regulations promoted an outdated perspective on what a meal is and (ii) vegetarianism should be introduced as an option in the nutritional standards for schools (Pētersone 2017). Meanwhile, the Ministry of Health that had developed the original health regulations was silent on the issue claiming that they were following the case and will change the regulations if necessary.

Much like in the first case, the object of the conflict was multiple and each side brought different facts to bear upon the issue in question. The school saw vegetarian diets as a practical way to be consistent with the ethical commitments of the children and their parents. The illegality of vegetarian diets was a matter of fact for the FVS, while it was a matter of concern for the school. Each side worked within a different framework (official requirements vs. contextually sensitive ethics).

\section{Case C: contested energy}

The development of biogas production in Latvia started in 2009 in response to renewable energy policy goals set by the European Union and the availability of generous public funding. A crucial stimulus for this development was the political decision to provide state support for green energy and distribute quotas to biogas producers at a higher-thanmarket price for the next 10 years, with decreasing support for the subsequent 10 years.

Entrepreneurs in the food sector and beyond responded by forming a grass-roots niche. A number of entrepreneursfarmers and energy companies (around 35-40 pioneers) entered the newly opened business field. The active core of producers established the Latvian Biogas Association and the whole network of biogas production soon grew as a diverse range of other actors and new entrants joined-the equipment suppliers, service providers, landless investors, financial institutions, municipalities, environmental agencies. Knowledge institutions such as universities and private consulting companies also became part of the biogas production network.
The biogas sector was mostly developed in a top-down manner (i.e. quotas, production permits, financial support mechanisms). The policies, regulations, public and private funding mechanisms were designed to be extremely favourable for innovation. The state created a secure niche for producers by distributing permits and making long-term financial commitments.

The purpose was to issue government permits to build new biogas plants, conclude long-term contracts with producers, secure green energy procurement and pay a premium price through the state energy company Latvenergo. The hope was that the new biogas plants would recycle agricultural waste, provide electrical and heat energy for public use (for example, heating of municipal buildings), stimulate the emergence of greenhouse businesses in rural areas and become economically self-sustainable.

Soon after the first bulk of biogas plants became operational, the production system started to expose its side effects-cultivation of monoculture crops as input for biogas stations, intensification of agricultural technologies, competition for land between farmers and energy producers, negative impacts on the environment and rural infrastructure. Originally, there was a hope that biogas plants would recycle agricultural waste; in reality many operations were detached from actual farming and captured land and biomass resources for producing energy. In addition, the business model was not economically sustainable as it depended excessively on public subsidies. A lot of controversy arose among the parties involved-farmers, energy producers, consumers, government agencies, regarding what were acceptable practices.

Three kinds of arguments were used in the debate about the complicated situation in the biogas sector and possible resolutions: economic, environmental and legal. From an economic point of view, farmers and their organisations complained about "land grabbing" by biogas companies and increasing compulsory green energy payments in the farms' electricity bills. Consumer organisations raised concerns regarding the system of compulsory green payments imposed on consumers. From the environmental perspective, small and organic farmers, agronomists, environmentalists and rural residents pointed at biodiversity loss and degradation of rural landscapes around biogas plants. In the legal realm, the government and biogas producers engaged in a dispute about possibilities, conditions and consequences of terminating the long-term financial commitment.

However, these debates failed to strike a balance between energy production, environmental protection and economic efficiency. Support was being reconsidered by the Ministry of Economics; however, withdrawal of the government from the agreement with biogas producers would be costly if the state lost against the biogas companies in court. For the government, electricity consumers and the majority of 
farmers it was much a stalemate situation as everybody had to contribute financially (except biogas producers).

Discussions over the last years had resulted in any significant improvement. This changed when ethical considerations such as social justice, legitimacy of public subsidies, equal treatment of all businesses, fair political decision-making, respect for consumer rights were introduced into the debate about adverse effects of a relatively sheltered niche of biogas production. Now the need for a more just and solution has been repeatedly voiced by consumer organisations, business associations, the Ministry of Economics and political parties, which deploy ethical arguments and not only economic, environmental or legal rationalisations. During the national parliament election campaign in 2018 all major political parties promised to abolish the system of compulsory green energy procurement from biogas plants.

The biogas production case illustrates the complexity of dilemmas, conflicts and lock-inns associated with the development of green energy production in agriculture. The case provides an example of "adulteration" of green energy production practices as a result of poorly managed policies. The case evolved over the last decade of actual implementation of green energy policies and the development of green energy production systems in Latvia, of which biogas is a considerable part. As the biogas sector expanded, the interests of producers, consumers, environmentalists, state authorities and other parties have been in constant collision. The situation changed when ethical concerns were actively introduced in the debate to challenge the existing regime of biogas production. As a result, alternative framings of the current situation and solutions for the biogas sector have been proposed which would make the sector economically and environmentally more sustainable.

\section{Analysis}

All three cases illustrate the presence and obstinacy of ethical concerns in the agri-food industry, and the challenges that public institutions face in governing them. While the list of actors and stakeholders is long, a common thread in all three case studies is the problematisation of the actions of public institutions. Each case represents a slightly different aspect of the tension between an ethics of sustainability and business-as-usual governance arrangements. Furthermore, all three cases illustrate the emergence of matters of concern in which different actors see the dispute in different terms (both ethically and ontologically) and produce different justifications for their actions.

In the Dogo case, participants focus on different aspects of an ever-evolving problem. Veterinarians and dog owners treat it as a dispute over a potentially dangerous brand of pet food, a brand that veterinarians themselves had in some cases distributed and recommended. For them, it is a question of food safety and corporate responsibility. The producer company sees it as a public relations problem and a campaign to tarnish their reputation-a campaign that is based on contentious evidence of their negligence and guilt. The media, though not unequivocally, treat the incident as a failure of public institutions to intervene and settle the affair. Public institutions, on the other hand, treated it as a minor incident and appeared to side with a significant local producer, giving precedence to economic interests and downplaying the importance of food safety as it relates to a non-human species.

In this case, public institutions failed to act decisively and generally were on the side of the producers, TS - a position that was problematic due to the ties between the party represented by the minister of agriculture and the owners of Dogo. Indeed, by treating it as an economic problem and disputing the pertinence and significance of the facts presented by the veterinarians, TS and several public institutions sought to challenge the very idea that there is a matter about which people should be concerned. Food safety, corporate responsibility and the rights of dogs and dog owners were in a subordinate position to the continued competitiveness of a local business. This position, however, was based on a contestation of what the other side saw as matters of fact-namely, that the deaths were most likely in some way connected to Dogo.

In the Ikškile case, the parties involved treated the vegetarian diet differently. To the people representing the school it was a way to combine practical considerations (price, lack of equipment) and a moral commitment to environmental sustainability. While not exclusively framed in ethical terms, the decision to make the switch to a vegetarian diet was, nonetheless, an expression of ethical commitment. For the FVS, on the other hand, it was primarily a legal issue of enforcing regulations. For them, the legal status of a vegetarian diet in schools was a matter of fact-a settled state of affairs that had to be respected. For the school, it became a matter of concern, exacerbated, in part, by the problematic nature of the procedure that would make the vegetarian diet formally acceptable_ obtaining a document which says that their pupils are ill. This has stimulated the introduction of additional expert testimony with the aim of challenging the existing nutritional guidelines and redefining the state of affairs and the matters of fact upon which the Food and Veterinary Service bases its actions. Again, however, public institutions remain agnostic as to the existence of matters of concern.

The biogas case is the clearest illustration of a clash between different forms of sustainability, with different parties treating biogas as a matter of concern for different reasons and a different understanding of what it means in practice (e.g. a way to make money vs. a loss of biodiversity). 
While the government sought to introduce a new form of energy-production that would be better for the environment, the governance framework proved to be flawed and created further problems for environmental, economic and social sustainability. In this case, the tension between different forms of sustainability created a stalemate, as the friction and incompatibility between numerous social goals appeared to be too great. The re-framing of the issue in terms of collective values and social ethics managed to reignite the debate and stimulate work towards an alignment of multiple goals and interests, but it remains to be seen what position the government will ultimately take, and what priorities will be articulated. The biogas case illustrates a clash in matters of concern and difficulties to resolve these by better coordinated policies. A summary of configuration of ethical dispute is provided in Table 1.

Case studies show that matters of concern can be different for different groups, and the same can be said for matters of fact. However, our case studies show different situations. In the first case study there is no difference about matters of concern (or, they are only related to the degree of precaution to be taken in relation to the costs and benefits of withdrawing a suspect food). The struggle is over the credibility of evidence, and the need for reliable third parties and reliable media. In the second case study matters of concern partially overlap (children's health) but not fully (i.e. concern for the environment). What is debated is the evidence regarding the healthiness of vegetarian diets. This is a case where better evidence could bring to a win-win situation. The third case raises the issue of trade-offs between different dimensions of sustainability. Here sustainability is a 'consensus frame', but each of the involved actors provides a different interpretation and relies on entrenched matters of fact.

\section{Discussion and conclusions}

Approaching governance arrangements in the agri-food sector from the perspective of ethics is complicated by the fact that any analysis will be influenced by certain background assumptions that shape conception of ethical conduct. However, the nature of the agri-food systems means that it requires considering the impact of particular provisioning systems and policy instruments in terms of their correspondence to collective goals such as social justice and sustainability.

We have looked at three cases of ethical dispute in Latvia from the perspective of Bruno Latour's distinction between matters of fact and matters of concern, and illustrated different scenarios of ethics-driven change motivated by concerns for social justice and sustainability. We noted that competing interests, factual uncertainty and entrenched practices are hurdles that complicate ethical 
deliberation, alliance building and collective agreement. Public institutions may have passive and more active role as moderators of the conflict and promoters of new ethical practices.

\section{Shared ethics}

This, we argue, is due to the multiplicity of renderings of a phenomenon that emerge when people do not share a common vision of a particular state of affairs, which is further exacerbated by different values and interests. Approaching ethical disputes from the perspective of matters of concern reveals that the interpretations that particular agents bring to the table are a complex mesh of conflicting ethical and ontological commitments that are obstinate and complicate the formation of consensus.

All three cases are ontologically multiple both because of the interests of the individual participants and the discrepant renderings of what to outsiders may appear to be the same state of affairs. In the case of Dogo, the pronouncements of veterinarians are both a public outcry against a health hazard and a public relations campaign. In the case of Ikškile, a vegetarian diet is both morally desirable and illegal. In the biogas case, it is both a source of income and green energy, and a burden on taxpayers and the surrounding rural areas.

Consequently, approaching the role of ethics in terms of matters of concern shows that decisive actions by public institutions would entail support for a particular vision (both moral and ontological) of the problem in question, and the needs and interests that this vision deems important. Resolving a matter of concern requires establishing a state of affairs articulated by a heterogeneous group with incompatible interests, and our cases illustrate the variety of potential outcomes.

For now, the Dogo scandal seems to illustrate a case of public officials implicitly supporting the producer, rather than the consumer, and therefore prioritising the economic dimension over the social dimension of sustainability (e.g. trust in the impartiality of public institutions and the accountability of businesses), and commercial interests over those of non-humans and their representatives. The school in Ikškile may well manage to redefine nutritional guidelines based on their ethical commitment to a vegetarian diet, thus creating a different environment for all future attempts to transition to a vegetarian diet and potentially contributing to the spread of more sustainable diets. The biogas case remains to be settled, but illustrates that ethical commitments can reinvigorate attempts to resolve obstinate problems, though it remains to be seen who will benefit.

\section{Distributed responsibility}

The three cases discussed in the article represent three attempts to restructure a part of a food system-either by fighting for animal rights (Dogo case), searching for linkages between social and environmental responsibility (Ikšķile case), or by aligning public costs and public gains (biogas case). In all examples, interpretations collide on what rules the food system should follow, but these disputes illustrate that there is a place for democratic negotiation on the moral objectives of food systems. On the one hand, these cases represent a system's failure to change; on the other-they are an illustration that actors are taking up matters of moral concern. The dominant models of doing things in contemporary food systems are morally neutral; the problem is-how to make these models more ethically engaged and responsible. This leads us to the question of responsibility. The three cases show the limits of responsibility: a rather limited set of actors stand for responsibility over a rather limited set of objects and perspectives. At the same time, the three examples illustrate attempts to broaden the set of actors that are taken into consideration when choices and links are made with regard to ethical compatriots. In the Dogo case the veterinarians formed an alliance with pet owners to represent the interests of animals, and approach industry with claims to improve food safety; in the case of Ikskile, parents, cooks and community activists called the government for more flexible nutritional regulations that would combine wellbeing, nutrition and environmental protection objectives in school meals; in the biogas case, a broad public-private alliance was formed calling to correct the green energy technological path according to ethical principles of justice and fairness. Gradual building of values communities or ethical alliances has been the process how shared responsibility was brought into food systems governance. However, collisions often happen between public and civic actors in ethical coalitions in making.

The role that governance and governments play in ethical disputes should be thoroughly examined (Kleine and Brightwell 2015). The three examples show different government responses to contested issues. In the biogas story, government officials pioneered the discussion on the necessary changes in the currently unsustainable production regime. In the case of school meals, the government did exactly the opposite and worked against the initiative group which called to change the existing state of affairs. In the Dogo, case the government distanced itself from the conflict.

Our analysis suggests that government (legislators, state authorities, regulative bodies) is an integral part of ethical shifts in food systems. However, not all actors in the government are all powerful or equally powerful. The government more than the NGOs and civic ethical communities is bound by previous decisions (matters of fact) 
and holds responsibility to ensure that the principles and procedures they have set are being followed. Furthermore, a handful of dishonest public officials may corrupt and reduce the efficiency of governing procedures. Finally, the government comparing with NGOs is more limited to operate in fuzzy and contested space of matters of concern and prefers to operate upon facts. This makes it more challenging for the government officials and institutions to engage in ethical projects and alliances for food system transformation.

\section{Ethical transparency}

In conclusion, ethical matters of concern are rife with contestation. In view of this, a transparent deliberation and decision-making process is crucial for ensuring public trust. Factual uncertainties, conflicts of interest and institutional inertia should be acknowledged. Furthermore, in resolving ethical disputes, public institutions should strive to exemplify an impartial and measured response that openly considers whether and how any proposed solution contributes to, or takes away from, all dimensions of sustainability, as represented by all the parties involved and affected.

We conclude that sharing ethical concerns and distributing responsibility in contemporary agri-food systems should take place through transparent procedures. Some actors in food systems offer their own ethical projects and create alliances with other similarly attuned actors. These bottom-up initiatives have to be combined with top-down responses and top-up ethicisation endeavours could be probed on a wider scale. The key thing here is the enforcement of accessible and participatory procedures of ethical deliberation that would allow for a broad representation of concerns and issues.

These considerations leave us with a set of complicated questions that need to be dealt with. Most likely the parties present in the three cases of ethical transformation after will identify different ways of being ethically responsible, and the ethical practices of today may become the nuisances of tomorrow. Should legislation become a part of moral solution? Our cases illustrate that outdated legislation can be an obstacle to change. Continued reflection and re-evaluation of the values and moral positions implicit in the standards, regulations and practices in the food system will be crucial for making food production and distributions systems more ethically sensitive.

Acknowledgements This research is supported by the Latvian Council of Sciences, Project SINFO [Social Innovation in Food Provision: Pathways to Sustainable Production and Consumption], Grant Nr. 1zp-2018/1-0344.
Open Access This article is distributed under the terms of the Creative Commons Attribution 4.0 International License (http://creativeco mmons.org/licenses/by/4.0/), which permits unrestricted use, distribution, and reproduction in any medium, provided you give appropriate credit to the original author(s) and the source, provide a link to the Creative Commons license, and indicate if changes were made.

\section{References}

Ambainis, Andris. 2016. Labojums Dogo aprēķinos suņa varbūtība saslimt pieaug starp 63 un 115 reizēm. Zinātnieka pārdomas. https://zinatniekapardomas.wordpress.com/. Accessed 10 Aug 2016.

Brunori, G., F. Galli, D. Barjolle, R. Van Broekhuizen, L. Colombo, M. Giampietro, J. Kirwan, T. Lang, E. Mathijs, D. Maye, K. De Roest, C. Rougoor, J. Schwarz, E. Schmitt, J. Smith, Z. Stojanovic, T. Tisenkopfs, and J.-M. Touzard. 2016. Are local food chains more sustainable than global food chains? Considerations for assessment. Sustainability 8 (5): No. 449.

Caradonna, J. 2014. Sustainability: A history. Oxford: Oxford University Press.

Food. 2030. 'Towards a common food policy for the EU' Framing paper for the EU food and farming forum 2018.

Galli, F., F. Bartolini, and G. Brunori. 2016. Handling diversity of visions and priorities in food chain sustainability assessment. Sustainability 8: 305.

Grivins, M., T. Tisenkopfs, V. Tikka, and T. Silvasti. 2018. Manoeuvring between regulations to achieve locally accepted results: Analysis of school meals in Latvia and Finland. Food Sec. https ://doi.org/10.1007/s12571-018-0856-6.

Jennings, B. 2010. Ethical aspects of sustainability, Minding Nature, 3 (1), https://www.humansandnature.org/ethical-aspects-ofsustainability.

Kaiser, M., and A. Algers. 2016. Food ethics: A wide field in need of dialogue. Food Ethics 1 (1): 1-7.

Kibert, C. J., L. Thiele, A. Peterson, and M. Monroe. 2011. The ethics of sustainability https://www.cce.ufl.edu/wp-content/uploa ds/2012/08/Ethics\%20of\%20Sustainability\%20Textbook.pdf.

Kirwan, J., D. Maye, and G. Brunori. 2017. Reflexive governance, incorporating ethics and changing understandings of food chain performance. Sociologia Ruralis 57 (3): 357377.

Kleine, D., and D. G. M. Brightwell. 2015. Repoliticising and scaling-up ethical consumption: Lessons from public procurement for school meals in Brazil. Geoforum 67: 135147.

Latour, B. 2004a. Why has critique run out of steam?: From matters of fact to matters of concern. Critical Inquiry 30 (2): 225-248.

Latour, B. 2004b. Politics of nature: How to bring the sciences into democracy. London: Harvard University Press.

Latour, B. 2005. Reassembling the social. Oxford: Oxford University Press.

Latour, B. 2008. What is the style of matters of concern. Assen: Royal Van Gorcum.

MacMillan, T., and E. Dowler. 2012. Just and sustainable? Examining the rhetoric and potential realities of UK food security. Journal of Agricultural and Environmental Ethics 25: 181204.

Mepham, B. 1996. Food ethics. London: Routledge.

Mol, A. 2002. The body multiple: Ontology in medical practice. London: Duke University Press.

Morgan, K. 2010. Local and green, global and fair: The ethical foodscape and the politics of care. Environ. Plan. A 2010 42: 18521867.

Pētersone, Ilze. 2017. Par veǵetārismu sods un tiesas process. http:// www.la.lv/par-vegetarismu-sods-un-tiesas-process/. 
Thompson, P. B. 2007. "Ethical Bases of Sustainability". In Sustainable Food Production and Ethics, eds. W. Zollitsch, C. Winckler, S. Waiblinger, and A. Haslberger, 63-68. Wageningen: Wageningen Academic Publishers.

Thompson, P. B. 2016. The Emergence of Food Ethics. Food Ethics 1 (1): 61-74.

UK Health Forum. 2018. Public health and the food and drinks industry: The governance and ethics of interaction. Lessons from research, policy and practice. London: UKHF. https:// www.idrc.ca/sites/default/files/sp/Documents\%20EN/ukhfcasebook-jan18.pdf.

Vlaholias-West, E., K. Thompson, K. Chiveralls, and D. Dawson. 2018. The ethics of food charity. In Encyclopedia of food and agricultural ethics, eds. P. Thompson, and D. Kaplan, Dordrecht: Springer.

ZM. 2016. Māris Goldmanis: Piezīmes par "Dogo" sāgu. https://www. zm.gov.lv/zemkopibas-ministrija/presei/maris-goldmanis-piezi mes-par-dogo-sagu?id=5388. Accessed 18 May 2016
Publisher's Note Springer Nature remains neutral with regard to jurisdictional claims in published maps and institutional affiliations.

Talis Tisenkopfs is a Senior Researcher at Baltic Studies Centre and Professor of Sociology at University of Latvia, Latvia.

Emils Kilis is a Researcher at Baltic Studies Centre, Latvia.

Mikelis Grivins is a Researcher at Baltic Studies Centre, Latvia.

Anda Adamsone-Fiskovica is a Researcher at Baltic Studies Centre, Latvia. 